\title{
Timing of transplantation of autologous bone marrow derived mesenchymal stem cells for treating myocardial infarction
}

\author{
CHEN YiHuan ${ }^{\dagger}$, TENG XiaoMei ${ }^{\dagger}$, CHEN WeiQian, YANG JunJie, YANG ZiYing, \\ YU YunSheng \& SHEN ZhenYa*
}

Department of Cardiovascular Surgery of the First Affiliated Hospital \& Institute for Cardiovascular Science of Soochow University, Suzhou 215006, China

Received August 7, 2013; accepted October 2, 2013; published online January 14, 2014

\begin{abstract}
It is still unclear whether the timing of intracoronary stem cell therapy affects the therapeutic response in patients with myocardial infarction. The natural course of healing the infarction and the presence of putative homing signals within the damaged myocardium appear to favor cell engraftment during the transendothelial passage in the early days after reperfusion. However, the adverse inflammatory environment, with its high oxidative stress, might be deleterious if cells are administered too early after reperfusion. Here we highlight several aspects of the timing of intracoronary stem cell therapy. Our results showed that transplantation of bone marrow mesenchymal stem cells at 2-4 weeks after myocardial infarction is more favorable for reduction of the scar area, inhibition of left ventricular remodeling, and recovery of heart function. Coronary injection of autologous bone marrow mesenchymal stem cells at 2-4 weeks after acute myocardial infarction is safe and does not increase the incidence of complications.
\end{abstract}

bone marrow mesenchymal stem cells (BMSCs), cell transplantation, myocardial infarction

Citation: $\quad$ Chen YH, Teng XM, Chen WQ, Yang JJ, Yang ZY, Yu YS, Shen ZY. Timing of transplantation of autologous bone marrow derived mesenchymal stem cells for treating myocardial infarction. Sci China Life Sci, 2014, 57: 195-200, doi: 10.1007/s11427-013-4605-y

Coronary interventional techniques and coronary artery bypass surgery are important solutions for myocardial revascularization in patients with coronary artery disease, and can significantly enhance the blood supply to the myocardium. However, they cannot significantly improve myocardial remodeling and heart failure in patients by increasing the number of working cardiomyocytes in the necrotic region. In recent years, with the development of molecular biology and cell biotechnology techniques, cell therapy has caught the attention of researchers around the world. After transplantation, cells can survive, proliferate, and replace the necrotic myocardium, thereby improving heart function. In 2001, Strauer et al. [1] first reported the clinical applica-

$\dagger$ Contributed equally to this work

*Corresponding author (email: uuzyshen@ aliyun.com) tion of stem cell transplantation for improving the heart function of patients with myocardial infarction (MI). Thus, promising clinical outcomes using stem cell transplantation for treatment of ischemic heart diseases have been reported by numerous medical research centers.

However, a number of problems remain to be resolved, such as determining the subtype and quantity of the transplanted cells, and the timing of transplantation. Strauer et al. [2] believed that mononuclear cells in the bone marrow consist of many cell types, and that their function is better than the solo application of a certain subgroup. However, mononuclear cells in the bone marrow contain a smaller number of effector cells, which may influence the effects after transplantation. In 2002, Toma et al. [3] found that amplified adult mesenchymal stem cells transplanted into 
cardiac muscle were able to differentiate into cardiomyocytes. This finding provided a feasible basis for the application of mesenchymal stem cells in cell therapy. Through a comparative study of different numbers of transplanted cells, Tambara et al. [4] found that the effects of replacing the infarcted myocardium and revascularization using $5 \times 10^{7}$ cells were better than those using $5 \times 10^{6}$ and $5 \times 10^{5}$ cells.

Besides the subtypes and quantities of the transplanted cells, the timing of transplantation is another important factor that may influence the effects of the treatment. The present study aimed to find out the optimal time point after the occurrence of acute MI for cell transplantation to provide patients with the maximum benefit. To address this issue, preclinical and clinical research studies were conducted.

\section{Materials and methods}

\subsection{Animal model preparation}

All surgical procedures were performed using Taihu Meishan pigs (three months of age; $24.5 \pm 2.9 \mathrm{~kg}$ ) provided by the Animal Laboratory Center in Soochow University. Experimental MI was induced by a gelatin sponge embolus pushed to the second diagonal branch of the left anterior descending coronary artery as previously described [5].

Bone marrow mesenchymal stem cells (BMSCs) were injected into the coronary artery of the pigs at various time points after MI. The pigs were randomly divided into five groups (n=5): (i) at three hours after MI; (ii) at one day after MI; (iii) at three days after MI; (iv) at two weeks after MI; and (v) at four weeks after MI. Control groups were treated with Dulbecco's modified Eagle's medium (DMEM) instead of BMSCs.

In addition, pigs were treated with pyrrolidine dithiocarbamate (PDTC) combined with BMSCs after MI. The pigs were randomly divided into four groups $(n=5)$ : PDTC + BMSC group: PDTC $\left(100 \mathrm{mg} \mathrm{kg}^{-1}\right)$ was intravenously injected at one hour after MI, and BMSCs $\left(1 \times 10^{7} / 5 \mathrm{~mL}\right)$ were injected into the coronary artery at one day after MI; BMSC group: physiological saline was intravenously injected at one hour after MI, and BMSCs $\left(1 \times 10^{7} / 5 \mathrm{~mL}\right)$ were injected into the coronary artery at one day after MI; PDTC group: PDTC $\left(100 \mathrm{mg} \mathrm{kg}^{-1}\right)$ was intravenously injected at one hour after MI, and $5 \mathrm{~mL}$ of physiological saline was injected into the coronary artery at one day after MI; control group: physiological saline was intravenously injected at one hour after MI, and $5 \mathrm{~mL}$ of physiological saline was injected into the coronary artery at one day after MI.

\subsection{Cell culture and transplantation}

BMSCs were isolated from swine bones and expanded as previously described [6]. The BMSCs were transplanted into MI models. Five milliliters of the stem cell suspension (5 $\mathrm{mL}$ of DMEM in the DMEM groups) was injected into the left coronary artery using a catheter.

\subsection{Evaluation of cardiac function}

Stroke volume (SV) and end-diastolic wall thickness (EDWT) were analyzed by cardiac MRI. Left ventricular end-diastolic diameter (LVEDd), left ventricular endsystolic diameter (LVEDs), and ejection fraction (EF) were analyzed by cardiac ultrasonography in each group prior to MI, prior to cell transplantation, and after cell transplantation. A chart blood pressure module was used to analyze the pressure curve and perform the following calculations: left ventricular developed pressure $(\mathrm{LVDP})=\mathrm{left}$ ventricular systolic peak pressure (LVSP)-left ventricular end-diastolic pressure (LVEDP); left ventricular maximum shrinkage rate change value $(+\mathrm{dp} / \mathrm{dtmax})$; and left ventricular maximum relaxation rate of change value (-dp/dtmax).

Myocardial perfusion was assessed by MRI, which clearly showed the range of acute MI and the maximum level of old MI, and was used to measure the thinning edge length and left ventricular perimeter. The infarction size was calculated by the percentage of the fibrosis length to the perimeter of the left ventricle.

\subsection{Enzyme-linked immunosorbent assay (ELISA)}

Venous blood samples were collected at different times. Serum interleukin (IL)-10, tumor necrosis factor (TNF)- $\alpha$, C-reactive protein (CRP) were analyzed using ELISA kits (R\&D systems, USA).

\subsection{Clinical trials: selected cases and cell transplanta- tion}

Clinical research was undertaken in the previous two years, and was approved by the State Food and Drug Administration. Proliferated and purified autogenous BMSCs were used to provide cell therapy to 42 patients with acute MI. The average age of the patients was $64 \pm 7.6$ years. Cell transplantation was undertaken in these patients at the late stage of MI (four weeks). Coronary artery injection was adopted, with a dosage of $1 \times 10^{7}$ cells. Eight patients were chosen to undergo second cell transplantation at one month after the first transplantation, to observe the effects of multiple transplantations.

\subsection{Clinical trials: evaluation of cardiac function}

The safety of the cell transplantation was evaluated by hematological traits, kidney and liver functions, myocardial enzymes, electrocardiograms, and 24-h Holter examinations at one week, two weeks, and one month after transplantation. The effectiveness was evaluated by ultrasonography, serum brain natriuretic peptide (BNP) measured using ELISA kit (Sangon, China), and other methods. Recent endpoint as- 
sessment and clinical follow-up were undertaken at one month and one year after transplantation, respec- tively.

\subsection{Statistical analysis}

All data are expressed as the mean \pm SD. A $t$-test was used for statistical analyses $(\alpha=0.05)$. Values of $P<0.05$ were considered statistically significant.

\section{Results}

\subsection{Time window research on stem cell therapy for MI}

\subsubsection{Cardiac functional parameters detected by echocar-} diography results

Following MI, LVEDd and LVEDs were significantly increased, and EF was significantly decreased in each group. The control group and the acute phase (three-hour, one-day, three-day) groups showed no significant differences after transplantation $(P>0.05)$. LVEDd and LVEDs in the two-week and four-week groups were significantly reduced. EF was significantly increased in the two-week and four-week groups after transplantation, and the values in the four-week group were greater than those in the two-week group (Table 1).

\subsubsection{Left ventricular wall function and infarction size detected by cardiac MRI before and after MI}

The ventricular beat and myocardial perfusion were normal prior to MI. At four weeks after MI, left ventricular MRI indicated a thinned infarct wall, shortened $\mathrm{T} 2$ relaxation time, reduced myocardial signal, and weakened ventricular beat in the thinned segment. Dilatation was also obvious in the left ventricular chamber.

The wall thickness showed no significant differences between the acute phase (three-hour, one-day, three-day) groups and the control group. The two-week and four-week transplantation groups showed obviously thickened end walls compared with the acute phase groups and the control group, with a greater significant difference in the four-week group. The SV of the acute groups and control group was decreased compared with the data before transplantation (not shown here). The SV of the two-week and four-week groups was significantly increased compared with that of the control group and the acute phase groups (Table 2).

\subsection{PDTC treatment of acute MI}

\subsubsection{IL-10 levels before and after transplantation}

There were no significant differences in the serum IL-10 levels before $\mathrm{MI}$ in all groups $(P>0.05)$. The serum IL-10 level in the control group reached its highest point on day 7 , and decreased to the normal level by day 14 , with no significant difference compared with the data before MI $(P>0.05)$. The IL-10 levels in the PDTC group and combined group were higher than those in the control group $(P<0.05)$ (Table 3).

\subsubsection{TNF- $\alpha$ levels before and after transplantation}

The serum TNF- $\alpha$ levels before MI showed no significant differences in all groups $(P>0.05)$. The serum TNF- $\alpha$ level in the control group reached its highest point on day 3 , and decreased to the normal level by day 14 , with no significant difference compared with the data before MI $(P>0.05)$. The serum TNF- $\alpha$ levels in the PDTC group and combined group were lower than those in the control group at 1, 3, and 7 days after transplantation $(P<0.05)$ (Table 4$)$.

Table 1 Echocardiography at four weeks after BMSC transplantation ${ }^{\text {a) }}$

\begin{tabular}{|c|c|c|c|c|c|c|c|c|c|c|}
\hline \multirow{2}{*}{$\begin{array}{l}\text { Time of cell } \\
\text { transplantation }\end{array}$} & \multicolumn{2}{|c|}{$3 \mathrm{~h}$ after MI } & \multicolumn{2}{|c|}{$1 \mathrm{~d}$ after $\mathrm{MI}$} & \multicolumn{2}{|c|}{$3 \mathrm{~d}$ after $\mathrm{MI}$} & \multicolumn{2}{|c|}{2 weeks after MI } & \multicolumn{2}{|c|}{4 weeks after MI } \\
\hline & DMEM & MSCs & DMEM & MSCs & DMEM & MSCs & DMEM & MSCs & DMEM & MSCs \\
\hline LVEDs (mm) & $47.74 \pm 3.52$ & $46.64 \pm 3.32$ & $45.88 \pm 5.48$ & $46.21 \pm 4.12$ & $44.73 \pm 3.69$ & $45.62 \pm 4.42$ & $43.50 \pm 1.98$ & $36.76 \pm 3.02$ & $46.18 \pm 3.21$ & $30.82 \pm 2.42^{*}$ \\
\hline LVEDd (mm) & $56.90 \pm 2.26$ & $56.62 \pm 2.97^{*}$ & $55.79 \pm 3.56$ & $57.13 \pm 4.67^{*}$ & $54.17 \pm 2.86$ & $55.63 \pm 3.97 *$ & $55.30 \pm 3.40$ & $50.58 \pm 2.68$ & $55.10 \pm 2.37$ & $45.36 \pm 2.48^{* *}$ \\
\hline $\mathrm{EF}(\%)$ & $33.3 \pm 3.0$ & $35.5 \pm 4.2^{* * *}$ & $35.3 \pm 3.6$ & $36.2 \pm 4.2^{* *}$ & $34.6 \pm 3.4$ & $35.1 \pm 4.5^{* *}$ & $35.3 \pm 3.3$ & $43.8 \pm 3.1$ & $35.9 \pm 2.3$ & $52.8 \pm 3.2^{\#}$ \\
\hline
\end{tabular}

a) *, compared with the 2-week group, $P<0.05$. **, compared with the 2-week group, $P<0.05$. ※, compared with the 2-week and 4-week groups, $P<0.05$; compared with the DMEM group, $P>0.05$. $※$, compared with the 2 -week and 4-week groups, $P<0.05$; compared with the DMEM group, $P>0.05$. \#, compared with the 2 -week group, $P<0.05$.

Table 2 MRI at eight weeks after BMSCs transplantation ${ }^{\text {a) }}$

\begin{tabular}{|c|c|c|c|c|c|c|c|c|c|c|}
\hline \multirow{2}{*}{$\begin{array}{l}\text { Time of cell } \\
\text { transplantation }\end{array}$} & \multicolumn{2}{|c|}{$3 \mathrm{~h}$ after MI } & \multicolumn{2}{|c|}{$1 \mathrm{~d}$ after $\mathrm{MI}$} & \multicolumn{2}{|c|}{$3 \mathrm{~d}$ after MI } & \multicolumn{2}{|c|}{2 weeks after MI } & \multicolumn{2}{|c|}{4 weeks after MI } \\
\hline & DMEM & MSCs & DMEM & MSCs & DMEM & MSCs & DMEM & MSCs & DMEM & MSCs \\
\hline EDWT (mm) & $6.55 \pm 0.61$ & $6.88 \pm 0.76^{*}$ & $6.85 \pm 0.88$ & $6.78 \pm 0.72^{*}$ & $6.64 \pm 0.53$ & $6.45 \pm 0.65^{*}$ & $6.93 \pm 0.54$ & $7.51 \pm 0.81$ & $6.95 \pm 0.69$ & $8.44 \pm 0.55^{* *}$ \\
\hline $\mathrm{SV}$ (mL/beat) & $33.51 \pm 2.96$ & $34.5 \pm 2.31^{*}$ & $34.96 \pm 3.16$ & $34.85 \pm 3.33^{*}$ & $32.89 \pm 2.15$ & $32.88 \pm 2.79^{*}$ & $33.28 \pm 2.51$ & $37.89 \pm 2.86$ & $33.71 \pm 2.45$ & $41.64 \pm 2.47^{* *}$ \\
\hline Infarct area $(\%)$ & $40.60 \pm 3.44$ & $42.80 \pm 4.66$ & $41.58 \pm 3.74$ & $42.48 \pm 4.87$ & $41.63 \pm 3.24$ & $40.80 \pm 3.16$ & $42.20 \pm 3.83$ & $34.60 \pm 2.07$ & $43.60 \pm 3.64$ & $29.80 \pm 1.30^{\#}$ \\
\hline
\end{tabular}

a) *, compared with the 2 -week and 4-week groups, $P<0.05$. **, compared with the 2 -week group, $P<0.05$. $※$, compared with the 2 -week and 4 -week groups, $P<0.05$; compared with the DMEM group, $P>0.05$. $※ ※$, compared with the 2 -week group, $P<0.05$; compared with the DMEM group, $P<0.05$. \#, compared with the 2-week group, $P<0.05$. 


\subsubsection{CRP levels before and after transplantation}

The serum CRP levels before MI showed no significant differences in all groups $(P>0.05)$. The serum CRP level in the control group reached its highest point at three days after transplantation and decreased to the normal level by 14 days $(P>0.05)$. The serum CRP levels in the other groups showed similar patterns to the control group. The PDTC group and combined group had lower levels of IL-10 at 1, 3, and 7 days compared with the control group $(P<0.05)$ (Table 5).

\subsubsection{Echocardiography}

There were no significant differences in LVDP, +dp/dtmax, and $-\mathrm{dp} / \mathrm{dtmax}$ before $\mathrm{MI}$ in all groups $(P>0.05)$. All three indexes decreased after MI $(P<0.01)$. LVDP, + dp/dtmax, and -dp/dtmax in the combined group were increased at four weeks after transplantation compared with those of the control group $(P<0.05)$ (Tables 6-8).

\subsection{Clinical translation of cell transplantation}

The serum BNP level was significantly decreased at one month after transplantation $\left(478.15 \pm 232.07 \mathrm{pg} \mathrm{mL}^{-1}\right.$ vs. $\left.195.45 \pm 130.18 \mathrm{pg} \mathrm{mL}^{-1}, P<0.001\right)$. The EF was significantly increased at one month after transplantation $(41.3 \% \pm 12.3 \%$ vs. $49.7 \% \pm 13.9 \%, P<0.05)$, but decreased to the normal level at six months after transplantation $(41.3 \% \pm 12.3 \%$ vs. $43.1 \% \pm 12.4 \%, P>0.05)$ (Table 9). These findings indicated transient effects of cell transplantation.

Eight additional cases were chosen to undergo cell trans-

Table 3 Serum IL-10 levels before and after BMSCs transplantation $\left(\mathrm{pg} \mathrm{mL}^{-1}\right)^{\mathrm{a})}$

\begin{tabular}{|c|c|c|c|c|c|c|}
\hline Groups & Before infarction & After infarction & $1 \mathrm{~d}$ after transplantation & $3 \mathrm{~d}$ after transplantation & $7 \mathrm{~d}$ after transplantation & $14 \mathrm{~d}$ after transplantation \\
\hline Control & $17.772 \pm 1.86$ & $22.454 \pm 2.12^{*}$ & $25.776 \pm 2.43^{*}$ & $51.812 \pm 1.59^{*}$ & $84.422 \pm 2.06^{*}$ & $18.002 \pm 1.77$ \\
\hline PDTC & $17.9 \pm 1.34$ & $26.14 \pm 2.05^{* \#}$ & $49.826 \pm 1.32^{* \#}$ & $70.208 \pm 1.38^{* \#}$ & $85.164 \pm 1.35^{*}$ & $17.478 \pm 1.33$ \\
\hline Stem cell & $17.894 \pm 1.84$ & $22.45 \pm 2.05^{*}$ & $25.158 \pm 2.26^{*}$ & $51.48 \pm 1.46^{*}$ & $84.252 \pm 2.61^{*}$ & $18.144 \pm 0.96$ \\
\hline
\end{tabular}

a) *, compared with the data before MI, $P<0.05$. \#, compared with the control group, $P<0.05$.

Table 4 Serum TNF- $\alpha$ levels before and after BMSCs transplantation $\left(\mathrm{pg} \mathrm{mL}^{-1}\right)^{\mathrm{a}}$

\begin{tabular}{|c|c|c|c|c|c|c|}
\hline Groups & Before infarction & After infarction & $1 \mathrm{~d}$ after transplantation & $3 \mathrm{~d}$ after transplantation & $7 \mathrm{~d}$ after transplantation & $14 \mathrm{~d}$ after transplantation \\
\hline Control & $4.912 \pm 1.39$ & $5.722 \pm 1.45$ & $21.98 \pm 3.22^{*}$ & $22.6 \pm 4.58^{*}$ & $14.84 \pm 4.61^{*}$ & $8.18 \pm 1.83^{*}$ \\
\hline PDTC & $5.08 \pm 0.81$ & $5.844 \pm 0.84$ & $9.96 \pm 0.99^{\#}$ & $10.58 \pm 1.13^{\#}$ & $9.22 \pm 1.07^{\#}$ & $7.024 \pm 1.01$ \\
\hline Stem cell & $5.182 \pm 1.36$ & $5.28 \pm 1.18$ & $23.8 \pm 2.68^{*}$ & $24.62 \pm 2.45^{*}$ & $13.244 \pm 2.74^{*}$ & $6.94 \pm 0.83$ \\
\hline
\end{tabular}

a) *, compared with the data before MI, $P<0.05$. \#, compared with the control group, $P<0.05$.

Table 5 Serum CRP levels before and after BMSCs transplantation $\left(\mathrm{ng} \mathrm{mL}^{-1}\right)^{\mathrm{a}}$

\begin{tabular}{|c|c|c|c|c|c|c|}
\hline Groups & Prior to infarction & After infarction & 1d after transplantation & $3 \mathrm{~d}$ after transplantation & $7 \mathrm{~d}$ after transplantation & $14 \mathrm{~d}$ after transplantation \\
\hline control & $131.85 \pm 17.16$ & $162.35 \pm 11.15^{*}$ & $1476 \pm 97.49^{*}$ & $1739.6 \pm 97.25^{*}$ & $1355.4 \pm 81.73^{*}$ & $216.1 \pm 23.88^{*}$ \\
\hline PDTC & $132 \pm 12.82$ & $148.75 \pm 3.52^{*}$ & $362.5 \pm 27.9^{* \#}$ & $391.05 \pm 22.06^{* \#}$ & $322.7 \pm 28.62^{* \#}$ & $231.4 \pm 22.14^{*}$ \\
\hline Stem cell & $126.65 \pm 5.69$ & $157.2 \pm 14.84^{*}$ & $1529 \pm 142.96^{*}$ & $1556.6 \pm 170.49^{*}$ & $1138.2 \pm 117.24^{*}$ & $226.3 \pm 14.85^{*}$ \\
\hline
\end{tabular}

a) *, compared with the data before MI, $P<0.05$. \#, compared with the control group, $P<0.05$.

Table $6+\mathrm{dp} / \mathrm{dtmax}$ before and after BMSCs transplantation $\left(\mathrm{mmHg} \mathrm{s}^{-1}\right)^{\mathrm{a})}$

\begin{tabular}{cccc}
\hline Groups & Before MI & After MI & After transplantation \\
\hline Control & $6028.294 \pm 90.83$ & $2379.176 \pm 54.99^{*}$ & $2234 \pm 216.47^{*}$ \\
PDTC & $6095.08 \pm 140.12$ & $2492.136 \pm 135.8^{*}$ & $2337.988 \pm 181.16^{*}$ \\
Stem cell & $6134.636 \pm 127.25$ & $2503.012 \pm 96.36^{*}$ & $2321.774 \pm 225.24^{*}$ \\
Combined & $6226.876 \pm 200.51$ & $2416.328 \pm 177.07^{*}$ & $3547.702 \pm 374.42^{* *}$ \\
\hline
\end{tabular}

a) *, compared with the data before MI, $P<0.05$. \#, compared with the control group, $P<0.05$.

Table 7 -dp/dtmax before and after BMSCs transplantation $\left(\mathrm{mmHg} \mathrm{s}^{-1}\right)^{\mathrm{a})}$

\begin{tabular}{cccc}
\hline Groups & Before MI & After MI & After transplantation \\
\hline Control & $4869.922 \pm 316.23$ & $1662.588 \pm 75.85^{*}$ & $1546.08 \pm 131^{*}$ \\
PDTC & $4761.61 \pm 114.51$ & $1702.904 \pm 95.7^{*}$ & $1476.154 \pm 135.71^{*}$ \\
Stem cell & $4859.766 \pm 157.17$ & $1714.52 \pm 98.46^{*}$ & $1495.206 \pm 119.24^{*}$ \\
Combined & $4957.97 \pm 242.37$ & $1729.016 \pm 62.11^{*}$ & $2601.974 \pm 155.81^{*}$ \\
\hline
\end{tabular}

a) *, compared with the data before MI, $P<0.05$. \#, compared with the control group, $P<0.05$. 
Table 8 LVDP before and after BMSCs transplantation $(\mathrm{mmHg})^{\mathrm{a}}$

\begin{tabular}{cccc}
\hline Groups & Before MI & After MI & After transplantation \\
\hline Control & $128.286 \pm 2.56$ & $42.714 \pm 3.6^{*}$ & $41.328 \pm 2.48^{*}$ \\
PDTC & $130.376 \pm 4.93$ & $43.254 \pm 4.08^{*}$ & $42.376 \pm 4.05^{*}$ \\
Stem cell & $130.324 \pm 4.2$ & $40.334 \pm 2.75^{*}$ & $43.006 \pm 2.09^{*}$ \\
Combined & $130.38 \pm 4.41$ & $43.228 \pm 2.85^{*}$ & $73.868 \pm 2.61^{* \#}$ \\
\hline
\end{tabular}

a) *, compared with the data before MI, $P<0.05$. \#, compared with the control group, $P<0.05$.

Table 9 Serum BNP levels and EF before and after BMSC transplantation

\begin{tabular}{|c|c|c|c|c|c|c|c|}
\hline Groups & $\begin{array}{c}\text { Prior to } \\
\text { transplantation }\end{array}$ & $\begin{array}{c}1 \text { week after } \\
\text { transplantation }\end{array}$ & $\begin{array}{l}2 \text { weeks after } \\
\text { transplantation }\end{array}$ & $\begin{array}{l}3 \text { weeks after } \\
\text { transplantation }\end{array}$ & $\begin{array}{l}1 \text { month after } \\
\text { transplantation }\end{array}$ & $\begin{array}{l}6 \text { months after } \\
\text { transplantation }\end{array}$ & $\begin{array}{c}1 \text { year after } \\
\text { transplantation }\end{array}$ \\
\hline $\begin{array}{c}\mathrm{BNP} \\
\left(\mathrm{pg} \mathrm{mL}^{-1}\right)\end{array}$ & $478.15 \pm 232.07$ & $402.08 \pm 209.16$ & $348.81 \pm 205.87$ & $312.90 \pm 199.39$ & $195.45 \pm 130.18$ & $488 \pm 224.12$ & $503 \pm 201.85$ \\
\hline
\end{tabular}

plantation at one month after the first transplantation. The EF was further improved $(39.3 \% \pm 11.3 \%$ vs. $51.9 \% \pm 14.3 \%$, $P<0.05)$, indicating a better outcome after multiple transplantations.

\section{Discussion}

Animal studies and preclinical research have demonstrated that bone marrow stem cell transplantation can improve ischemic heart function [2,7]. Owing to the advantages of bone marrow stem cells, such as convenient extraction, adequate number of cells, high survival rate after transplantation, and low immunogenicity, these cells have become one of the more commonly used cells in cell transplantation.

However, at which time point and what kind of transplantation method could benefit the individuals best have been the most concerned topic in cell transplantation. In the time window research on the therapeutic effects using stem cells for MI, we found that the LVESD, LVEDD and EDWT were not significantly changed comparing the three-hour, one-day and three-day cell transplantation groups with the control groups; however, these values were significantly improved when the two-week and four-week cell transplantation groups were compared with the acute transplantation groups and the control groups; and the absolute values of the reduction of fibrosis area were significantly higher in the four-week cell transplantation group than in the two-week and acute transplantation groups and the control groups. The data indicated that transplantation of MSCs in the non-acute phase could partially reverse cardiac dilation, delay LV remodeling and thus improve heart function.

It is reported that the survival and differentiation abilities of transplanted cells were severely inhibited due to local tissue ischemia, hypoxia, strong oxidative stress and inflammatory responses at one day after MI, and that the biological effect of the transplanted cells was dramatically weakened possibly because of the disastrous effect of inflammation [8]. Whereas cell transplantation had an improved efficacy at two weeks after MI, which was possibly attributed to that the time point of cell transplantation was chosen after the fading inflammation but before scar formation [9]. Schenk et al. [10] found that high expression of monocyte chemotactic protein-3 can promote homing of BMSCs to the heart at one month after MI. Our results also showed that the indicators in the four-week transplantation group were superior to those in the other groups, which was consistent with the above data.

The myocardial microenvironment plays an important role in the localization and differentiation of BMSCs after MI. If the myocardial microenvironment after MI is improved by regulating inflammation, the efficacy of cell transplantation can be significantly enhanced. Nuclear factor $(\mathrm{NF})-\kappa \mathrm{B}$ is a multigene regulatory factor in eukaryotic cells, and is involved in many biological processes, including regulation of innate and adaptive immune responses, cell growth, and apoptosis [11]. Oxygen free radicals regulate the transcription activity of NF- $\mathrm{KB}$ [12]. PDTC is a stable antioxidant compound that inhibits the production of TNF-induced oxygen-derived free radicals and NF- $\kappa B$ activity $[13,14]$. In this study, we inhibited NF- $\kappa B$ activation and reduced the level of inflammation by injecting PDTC.

In our study we used TNF- $\alpha$, CRP and IL-10 to reflect the inflammation level. TNF- $\alpha$ is believed to play roles in antitumor activity, immune modulation and inflammation, etc. TNF- $\alpha$ is expressed in many types of cells but primarily in macrophage cells in response to immunological challenges such as bacteria (lipopolysaccharides), viruses, parasites, mitogens and other cytokines. TNF- $\alpha$ appears to be directly toxic to vascular endothelial cells. Other actions of TNF- $\alpha$ include stimulating growth of human fibroblasts and other cell lines, activating polymorphonuclear neutrophils and osteoclasts, and induction of interleukin-1, prostaglandin E2 and collagenase production. CRP is a sensitive indicator of tissue injury. Measuring and charting CRP values can prove useful in determining disease progress or the effectiveness of treatments. The anti-inflammatory effect of IL-10 was confirmed in many in vitro and in vivo studies. IL-10 played a protective role in animal models of ischemia reperfusion and burn injury, through reducing the reactions of inflammatory factors and thus minimizing mortality. In the control group, the concentration of serum TNF- $\alpha$ and $\mathrm{CRP}$ rapidly increased several hours after MI, peaked at one 
and three days after MI, reached a platequ and then decreased, and returned to the normal level at 14 days after MI. The stem cell group had a similar tendency with the control group. While in the combined group and the PDTC groups, the increment of serum TNF- $\alpha$ and CRP level apparently slowed down, and the peak values were deduced $(\mathrm{P}<0.05)$, suggesting that the inflammatory level was dramatically reduced inside the animals after using PDTC.

In 2001, Hamano et al. [15] injected autologous bone marrow stem cells into the ischemic myocardium during coronary artery bypass graft surgery in five patients with old MI. They found that long-term improvement in myocardial perfusion occurred in three patients, while no significant changes in the other two cases at one-year follow-up. Arrhythmia, myocardial calcification, and neonatal tumors did not occur in the five patients. Suárez et al. [16] performed therapy with bone marrow mononuclear cells for 19 patients with chronic MI. At six-month follow-up, they found that the clinical symptoms and cardiac function had improved to some extent, and that these improvements were retained for the subsequent six months. BNP can be used for screening and prognosis of heart failure. It is typically increased in patients with left ventricular dysfunction, with or without symptoms. The net effect of BNP is a decrease in blood volume, which lowers systemic blood pressure and afterload, yielding an increase in cardiac output, partly due to a higher ejection fraction. In the present study, the serum BNP level was significantly decreased and the left ventricular EF was apparently increased at one month after the transplantation. Meanwhile no serious complications occurred after the transplantation of BMSCs. These findings are consistent with the results of Mukoyama et al. [17].

Regarding the long-term effect of cell transplantation, our study suggested that the left ventricular EF in patients with chronic MI was apparently increased at one month after transplantation, but the improvement was not apparent at six months, and that the left ventricular EF at 12 months showed no apparent difference compared with that before the transplantation, which was consistent with the results of the BOOST trial [18]. It is suggested that the effects of stem cell transplantation are short-term and mono intracoronary transplantation of MSCs has no long-term effect on the improvement of LV function, whereas multiple transplantations had better effects than a single transplantation. Therefore, the long-term therapeutic effects of cell transplantation could be maintained by multiple transplantations and the underlying mechanism requires further investigation.

1 Strauer BE, Brehm M, Zeus T, Gattermann N, Hernandez A, Sorg RV, Kögler G, Wernet P. Intracoronary, human autologous stem cell transplantation for myocardial regeneration following myocardial infarction. Dtsch Med Wochenschr, 2001, 126: 932-938

2 Strauer BE, Brehm M, Zeus T, et al. Repair of infarcted myocardium by autologous intracoronary mononuclear bone marrow cell transplantation in humans. Circulation, 2002, 106:1913-1918
3 Toma C, Pittenger MF, Cahill KS, Byrne BJ, Kessler PD. Human mesenchymal stem cells differentiate to a cardiomyocyte phenotype in the adult murine heart. Circulation, 2002, 105: 93-98

4 Tambara K, Sakakibara Y, Sakaguchi G, Lu F, Premaratne GU, Lin $\mathrm{X}$, Nishimura K, Komeda M. Transplanted skeletal myoblasts can fully replace the infarcted myocardium when they survive in the host in large numbers. Circulation, 2003, 108(Suppl 1): II259-263

5 Yu YS, Shen ZY, Ye WX, et al. AKT-modified autologous intracoronary mesenchymal stem cells prevent remodeling and repair in swine infarcted myocardium. Chin Med J (Engl), 2010, 123: 1702-1708

6 Wakitani S, Saito T, Caplan AI. Myogenic cells derived from rat bone marrow mesenchymal stem cells exposed to 5-azacytidine. Muscle Nerve, 1995, 18: 1417-1426

7 Frangogiannis NG, Mendoza LH, Lewallen M, Michael LH, Smith $\mathrm{CW}$, Entman ML. Induction and suppression of interferon-inducible protein 10 in reperfused myocardial infarcts may regulate angiogenesis. FASEB J, 2001, 15: 1428-1430

8 Kofidis T, de Bruin JL, Yamane T, Tanaka M, Lebl DR, Swijnenburg RJ, Weissman IL, Robbins RC. Stimulation of paracrine pathways with growth factors enhances embryonic stem cell engraftment and host specific differentiation in the heart after ischemic myocardial injury. Circulation, 2005, 111: 2486-2493

9 Li RK, Mickle DA, Weisel RD, Rao V, Jia ZQ. Optimal time for cardiomyocyte transplantation to maximize myocardial function after left ventricular injury. Ann Thorac Surg, 2001, 72: 1957-1963

10 Schenk S, Mal N, Finan A, Zhang M, Kiedrowski M, Popovic Z, McCarthy PM, Penn MS. Monocyte chemotactic protein-3 is a myocardial mesenchymal stem cell homing factor. Stem Cells, 2007, 25: 245-251

11 Perkins ND. Integrating cell-signalling pathways with NF-kappaB and IKK function. Nat Rev Mol Cell Biol, 2007, 8: 49-62

12 Bonello S, Zähringer C, BelAiba RS, Djordjevic T, Hess J, Michiels C, Kietzmann T, Görlach A. Reactive oxygen species activate the HIF-1alpha promoter via a functional NFkappaB site. Arterioscler Thromb Vasc Biol, 2007, 27: 755-761

13 Sarkar A, Sreenivasan Y, Ramesh GT, Manna SK. beta-D-Glucoside suppresses tumor necrosis factor-induced activation of nuclear transcription factor kappaB but potentiates apoptosis. J Biol Chem, 2004, 279: 33768-33781

14 Dechend R, Fiebeler A, Park JK, Muller DN, Theuer J, Mervaala E, Bieringer M, Gulba D, Dietz R, Luft FC, Haller H. Amelioration of angiotensin II-induced cardiac injury by a 3-hydroxy-3-methylglutaryl coenzyme a reductase inhibitor. Circulation, 2001, 104: 576581

15 Hamano K, Nishida M, Hirata K, Mikamo A, Li TS, Harada M, Miura T, Matsuzaki M, Esato K. Local implantation of autologous bone marrow cell for therapeutic angiogenesis in patients with ischemic heart disease: clinical trial and preliminary results. Jpn Circ J, 2001, 65: 845-847

16 Suárez de Lezo J, Herrera C, Romero MA, Pan M, Jiménez R, Carmona D, Segura JM, Nogueras S, Mesa D, Suárez de Lezo J, Pavlovic D, Ojeda S, Torres A. Functional recovery following intracoronary infusion of autologous mononuclear bone marrow cells in patients with chronic anterior myocardial infarction and severely depressed ventricular function. Rev Esp Cardiol, 2010, 63: 1127-1135

17 Mukoyama M, Nakao K, Hosoda K, Suga S, Saito Y, Ogawa Y, Shirakami $\mathrm{G}$, Jougasaki $\mathrm{M}$, Obata $\mathrm{K}$, Yasue $\mathrm{H}$, et al. Brain natriuretic peptide as a novel cardiac hormone in humans. J Clin Invest, 1991, 87: 1402-1412

18 Meyer GP, Wollert KC, Lotz J, Steffens J, Lippolt P, Fichtner S, Hecker H, Schaefer A, Arseniev L, Hertenstein B, Ganser A, Drexler $\mathrm{H}$. Intracoronary bone marrow cell transfer after myocardial infarction: eighteen months' follow-up data from the randomized, controlled BOOST (BOne marrOw transfer to enhance ST-elevation infarct regeneration) trial. Circulation, 2006, 14, 113: 1287-1294

Open Access This article is distributed under the terms of the Creative Commons Attribution License which permits any use, distribution, and reproduction in any medium, provided the original author(s) and source are credited. 